\title{
Plasma Degradation of Pesticides on the Surface of Corn and Evaluation of Its Quality Changes
}

\author{
Hongxia Liu *, Dingmeng Guo and Xinxin Feng
}

Citation: Liu, H.; Guo, D.; Feng, X. Plasma Degradation of Pesticides on the Surface of Corn and Evaluation of Its Quality Changes. Sustainability 2021, 13, 8830. https://doi.org/ $10.3390 /$ su13168830

Academic Editor: Biagio Bianchi

Received: 19 June 2021

Accepted: 3 August 2021

Published: 6 August 2021

Publisher's Note: MDPI stays neutral with regard to jurisdictional claims in published maps and institutional affiliations.

Copyright: (c) 2021 by the authors. Licensee MDPI, Basel, Switzerland. This article is an open access article distributed under the terms and conditions of the Creative Commons Attribution (CC BY) license (https:// creativecommons.org/licenses/by/ $4.0 /)$.
Department of Environmental Science and Engineering, School of Energy and Power Engineering, Xi'an Jiaotong University, Xi'an 710049, China; gdm970822@stu.xjtu.edu.cn (D.G.); fengxin2016@stu.xjtu.edu.cn (X.F.)

* Correspondence: hxliu72@xjtu.edu.cn

\begin{abstract}
Plasma is a surface decontamination tool that is widely used in the food fields for pesticide degradation. In this study the effect of plasma on pesticide elimination from the surface of corn and the corn quality changes were tested as functions of power, air flow rate, treatment time, and frequency. Results indicated that plasma treatment for $60 \mathrm{~s}$ at $1000 \mathrm{~mL} \cdot \mathrm{min}^{-1}$ air flow rate, power of $20 \mathrm{~W}$, and frequency of $1200 \mathrm{~Hz}$, achieved the largest degradation efficiency up to $86.2 \%$ for chlorpyrifos and $66.6 \%$ for carbaryl, both of which were below the maximum residues limit of grains. Most importantly, after plasma treatment, there was a remarkable decrease $(p<0.05)$ in moisture content and starch content for treated corn compared with control. The acid value for treated corn showed a prominent increase $(p<0.05)$, but within the acceptable range of the standard. The vitamin $\mathrm{B}_{2}$ content of treated corn did not show a significant difference $(p>0.05)$. All results of this study demonstrated that plasma treatment is a promising technology with the ability to remove pesticide residues on corn while maintaining its quality within acceptable limits.
\end{abstract}

Keywords: plasma; degradation effect; corn nutrients; surface morphology

\section{Introduction}

The widespread use of pesticides in agriculture leads to pesticide residues on agricultural products. Due to bioaccumulation effects, poisonousness and the toxic effects of pesticides, the chronic consumption of treated agricultural products by humans and animals poses a significant threat to human health [1]. In recent years, concerns about pesticide residues in cereals have mainly focused on organophosphorus pesticides such as chlorpyrifos and triazophos [2]. Mahugija et al. [3] found 23.7\% of corn samples in Tanzania had detectable chlorpyrifos. Meanwhile, for the case of unpolished corn flour samples and corn samples, chlorpyrifos was found in high concentrations of up to $1.402 \mathrm{mg} \cdot \mathrm{kg}^{-1}$ and $3.8103 \mathrm{mg} \cdot \mathrm{kg}^{-1}$, respectively, far above the maximum residue limits (MRL). Thus, ensuring the edible safety of cereals has become a hot research topic that needs to be studied in China and the world.

Corn, as an important part of the dietary structure of humans and animals, was chosen as a research object in this study. Chlorpyrifos and carbaryl, two insecticides frequently used to control pests in corn were selected as degradation targets. Compared with traditional technologies, plasma has been extensively studied in the field of food surface decontamination, due to its distinct advantages such as low cost, wide operating conditions, compact and flexible equipment structure, no residues, high efficiency for pollutant elimination and retention of food quality [4-6]. For instance, Cong et al. [7] reported that the degradation efficiency of malathion on lettuces reached $53.1 \%$ after dielectric barrier discharge (DBD) plasma treatment. Dorraki et al. [8] used DBD plasma to degrade the insecticide diazinon on the surface of cucumbers. The results indicated that the content of diazinon on the surface of cucumber was lower than the detectable value, and only a slight local burning effect was produced on the cucumber surface. In 
addition, Sarangapani et al. [9] investigated the effect of DBD plasma on the elimination of pesticide on blueberries and their quality changes, revealing high efficiency for pesticide degradation as well as an increase in the contents of total phenol and flavonoid without effect on color and firmness. Therefore, plasma, as a promising technology, was selected to protect corn from the pollution of pesticides in this study. In order to facilitate industrial application, air was used as the working gas. The targets of this research are to analyze the plasma treatment efficacy for the elimination of pesticides (chlorpyrifos and carbaryl) on the surface of corn as a function of the operation conditions (power, air flow rate, treatment time and frequency) and the evaluation of the treated corn quality changes as a function of exposure time.

\section{Materials and Methods}

\subsection{Reagents and Materials}

Methanol (HPLC grade), acetonitrile, diiodomethane, ether, ethanol, hydrochloric acid, sodium hydroxide, lead acetate, benzene, potassium hydroxide and phenolphthalein were bought from Damao Reagent Co. Ltd. (Tianjin, China). High purity chlorpyrifos and carbaryl ( $\geq 99.5 \%$ ) standards were obtained from Dr. Ehrenstorfer GmbH (Augsberg, Germany). Corn was bought from a local market.

\subsection{Sample Preparation}

Methanol was used to prepare chlorpyrifos and carbaryl standards at $20 \mathrm{mg} \cdot \mathrm{L}^{-1}$ concentration each. Using an immersion method ensured a homogeneous distribution of pesticides on the corn surface as described by Misra et al. [10]. Corn samples were thus separately immersed into standard solutions of the two pesticides for $15 \mathrm{~s}$, and then air-dried at $25{ }^{\circ} \mathrm{C}$ for $60 \mathrm{~min}$ and the above operation repeated twice for plasma treatment.

\subsection{Plasma Treatment}

Figure 1 shows a diagram of an experimental setup for pesticide (chlorpyrifos and carbaryl) degradation on the corn surface. The device consisted of two aluminum electrodes, each of which was placed with a $1 \mathrm{~mm}$ thick glass dielectric barrier. One of the electrodes was connected to a high voltage nanosecond pulse power supply (HVP-20, Smart Maple Electronic Technology Co., Ltd., Xi'an, China. Voltage: 0-20 kV; pulse width: $0 \mathrm{~ns}-1 \mathrm{~ms})$ as a high voltage electrode and the other was connected to a ground electrode to ensure safety and produce plasma due to the increase of gas molecules' energy between the electrodes. Using high purity (99.99\%) air as the working gas, the corn was placed in the gap between the two electrodes for degradation experiments, which was set to $6 \mathrm{~mm}$. The contaminated samples (with chlorpyrifos or carbaryl) were divided into two parts: one part was the control (without plasma treatment). The other was the experimental group. Single factor experiments were designed to test the degradation effects of chlorpyrifos and carbaryl through changing the operating parameters such as power $(4-20 \mathrm{~W})$, air flow (150-1500 $\left.\mathrm{mL} \cdot \mathrm{min}^{-1}\right)$, discharge time (20-60 s), frequency (100-1200 Hz). Meanwhile, based on obtained optimal degradation parameters, the quality changes of treated corn as the function of treatment time in the plasma discharge zone were investigated. All these experiments on the degradation effects of pesticides were independently repeated three times.

\subsection{Determination of Pesticide Degradation}

We used $0.1 \mathrm{mg} \cdot \mathrm{L}^{-1}$ to $10 \mathrm{mg} \cdot \mathrm{L}^{-1}$ pesticide standard solutions to build standard curves for the tested pesticides. The linear correlation coefficients $\left(\mathrm{r}^{2}\right)$ were 0.9991 and 0.9986 for chlorpyrifos and carbaryl, respectively. The pesticides extraction method was as described by Liu [11], with slight modifications. The determination of the pesticides' (chlorpyrifos and carbaryl) concentration was performed using HPLC combined with a S3345 PDA detector (Sykam GmbH, Gewerbering, Eresing, Germany) and an Ultimate C18 LC column $(4.6 \times 250 \mathrm{~mm}, 5 \mu \mathrm{m}$; Welch Materials, Shanghai, China). Wang et al. [12]. and 
Yang et al. [13] have documented methods for the determination of the two pesticides. The LOD and LOQ of the pesticides were $0.05 \mathrm{mg} \cdot \mathrm{kg}^{-1}$ and $0.1 \mathrm{mg} \cdot \mathrm{kg}^{-1}$, respectively. The detection wavelength of chlorpyrifos was $289 \mathrm{~nm}$, and the detection wavelength of carbaryl was $221 \mathrm{~nm}$. With a $1.0 \mathrm{~mL} \cdot \mathrm{min}^{-1}$ flow rate, the mobile phase consisted of methanol and water at 4:1 and 45:55 for the quantification of chlorpyrifos and carbaryl, respectively. Data collection was processed using the Clarity software (Sykam GmbH).

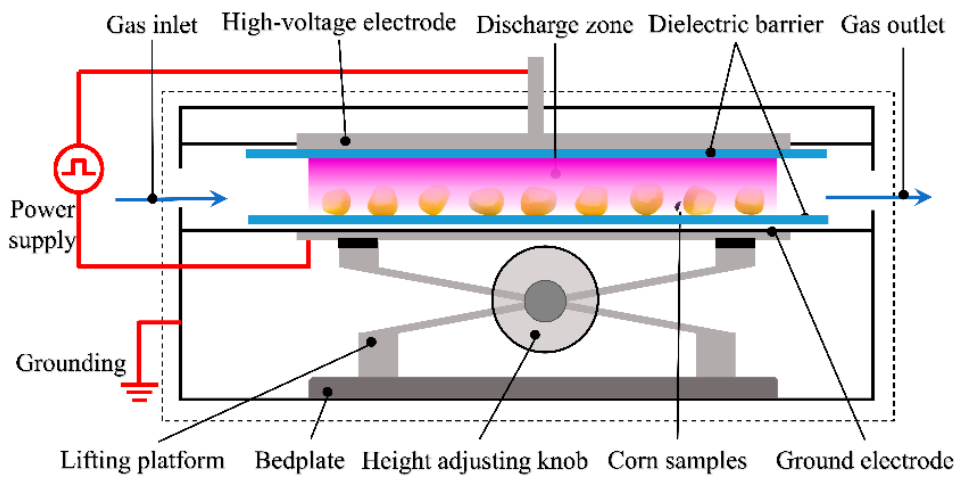

Figure 1. Schematic diagram of the experimental setup.

\subsection{Determination of Physical Changes of Corn Surface}

A field emission scanning electron microscope (FE-SEM, MAIA3, Tescan, Warrendale.PA, USA) was used to analyze the changes in surface morphology of corn treated by air-plasma. The contact angle of corn samples was measured by the sessile drop method through a DSA100s Optical Spinning Drop Tensiometer (SDT, KRUSS, Hamburg, Germany) to reveal the changes in the hydrophilicity of corn surface. Water and diiodomethane were selected as the test liquids. The surface free energy $\left(\gamma_{s}\right)$, polar component $\left(\gamma_{s}{ }^{p}\right)$ and dispersion component $\left(\gamma_{s}{ }^{d}\right)$ were calculated using the Owens method as described by Makiko et al. [14] to explain the reason for the change in hydrophilicity on the corn surface.

\subsection{Determination of Changes in Nutrients Contents of Corn}

The moisture content, starch content, fat acidity value and vitamin $B_{2}$ content were selected to determine the changes of corn nutrients contents. The moisture content, as a safety indicator for corn storage, was determined by the direct-drying method from the Chinese National Standard GB/T 5009.3-2016 [15]. The starch content, which can indicate the industrial application value of treated corn, was carried out by the acid-hydrolysis method of Chinese National Standard GB/T 5009.9-2016 [16]. Any changes in the fat acidity value of treated/untreated corn can indicate the effect of plasma on corn spoilage. High levels of corn fat acidity may cause corn to rot [17]. The acid value was measured by the titration method derived from Chinese National Standard GB/T 5510-2011 [18]. Vitamin $B_{2}$, found in the corn, is commonly acknowledged as a nutrient element for humans. Finally, the change in vitamin $B_{2}$ of treated corn was considered as the index expressing the damage of plasma to corn. The content of vitamin $B_{2}$ was determined by HPLC with a fluorescence detector (Waters 2695-2475, Milford, MA, USA) as recorded in Chinese National Standard GB/T 5009.85-2016 [19]. The mobile phase was sodium acetate solution $\left(0.05 \mathrm{~mol} \cdot \mathrm{L}^{-1}\right)$ methanol (65:35). A C18 column was used. The excitation wavelength was $462 \mathrm{~nm}$ and the emission wavelength was $522 \mathrm{~nm}$.

\subsection{Statistical Analysis}

The experiments on contact angle were repeated measured six times, while other pesticide degradation and nutrient content experiments were carried out three times, independently. All data were statistically analyzed by one-way ANOVA using SPSS version 20 (IBM, Armonk, New York, USA) choosing $p<0.05$ as statistical significance to compare the significance among samples and using LSD as post-hoc method. 


\section{Results}

\subsection{Quantification of Pesticides Degradation}

The initial concentrations of chlorpyrifos and carbaryl in control corn samples were $1.93 \pm 0.02 \mathrm{mg} \cdot \mathrm{kg}^{-1}$ and $1.89 \pm 0.01 \mathrm{mg} \cdot \mathrm{kg}^{-1}$, respectively. The elimination efficacy of plasma treatment of pesticides on the surface of corn is shown in Figure 2. Considering the operation conditions of the plasma system, the dissipation effect of the two pesticides was determined as a function of discharge power, air flow rate, treatment time and frequency, as seen in Figure $2 \mathrm{a}-\mathrm{d}$.

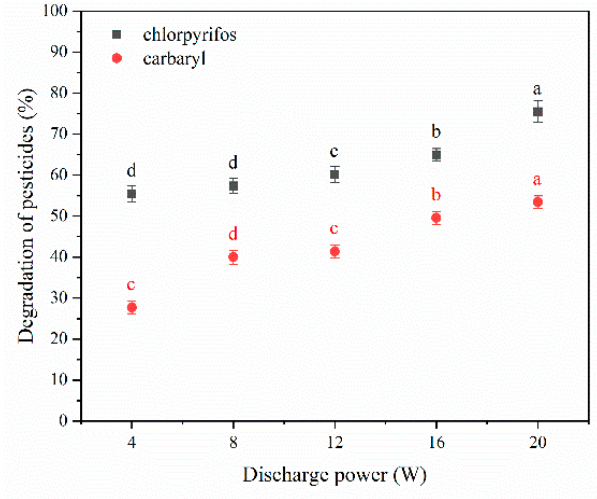

(a)

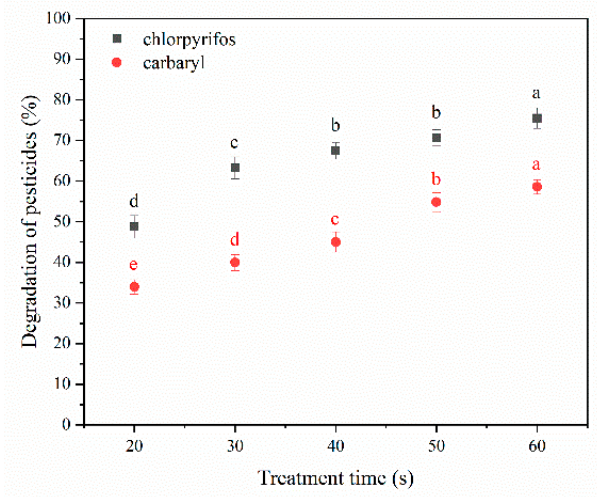

(c)

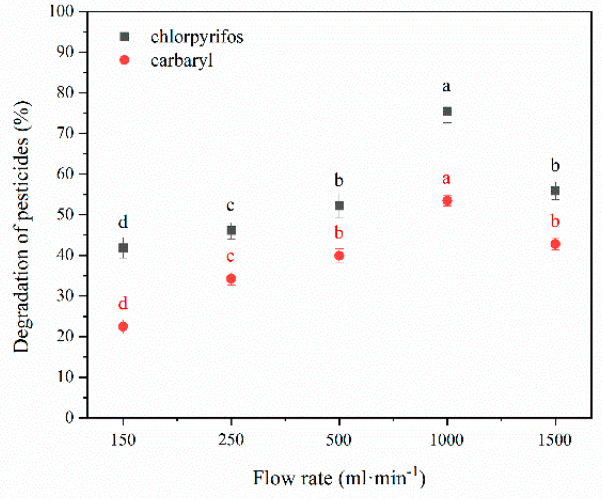

(b)

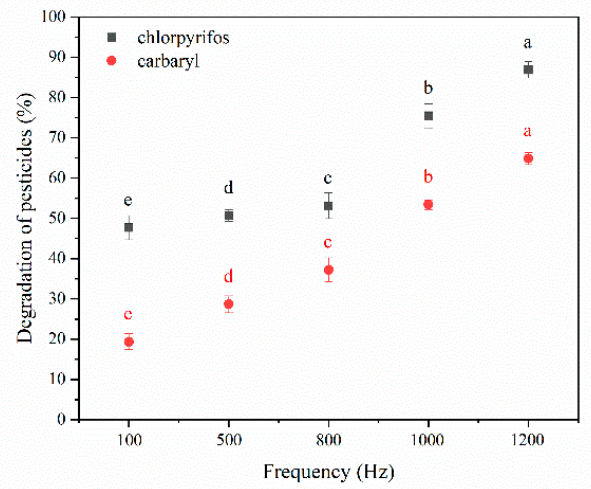

(d)

Figure 2. The effects of air-plasma on pesticide degradation on corn surface under different operation conditions (a) discharge power (at $1000 \mathrm{~mL} \cdot \mathrm{min}^{-1}$ fixed air flow rate, $60 \mathrm{~s}$ treatment time and $1000 \mathrm{~Hz}$ frequency) (b) flow rate (at $20 \mathrm{~W}$ discharge power, $60 \mathrm{~s}$ treatment time and $1000 \mathrm{~Hz}$ frequency) (c) treatment time (at $20 \mathrm{~W}$ discharge power, $1000 \mathrm{~mL} \cdot \mathrm{min}^{-1}$ fixed air flow rate and $1000 \mathrm{~Hz}$ frequency) (d) frequency (at $20 \mathrm{~W}$ discharge power, $1000 \mathrm{~mL} \cdot \mathrm{min}^{-1}$ fixed air flow rate and $60 \mathrm{~s}$ treatment time).

\subsubsection{Discharge Power}

At $1000 \mathrm{~mL} \cdot \mathrm{min}^{-1}$ fixed air flow rate, $60 \mathrm{~s}$ treatment time and $1000 \mathrm{~Hz}$ frequency, the degradation effect of plasma on the two pesticides as a function of discharge power was investigated. As shown in Figure 2a, a significant degradation $(p<0.05)$ of chlorpyrifos and carbaryl could be obtained due to the increase of plasma discharge power. The degradation effect of chlorpyrifos and carbaryl reached $75.8 \%$ and $56.7 \%$, respectively, obtaining the highest removal efficacy at a discharge power of $20 \mathrm{~W}$. Besides, regardless of discharge power, a higher degradation efficiency of chlorpyrifos than carbaryl was observed under the same plasma treatment parameters. 


\subsubsection{Air Flow Rate}

At a treatment time of $60 \mathrm{~s}$, frequency of $1000 \mathrm{~Hz}$ and optimal discharge power of $20 \mathrm{~W}$, Figure 2 shows the effect of plasma air flow rate on the degradation of chlorpyrifos and carbaryl. It was demonstrated that the degradation impact of pesticides initially showed significance $(p<0.05)$ with the increasing of air flow rate from $150 \mathrm{~mL} \cdot \mathrm{min}^{-1}$ to $1000 \mathrm{~mL} \cdot \mathrm{min}^{-1}$ and then decreased with further increase of the air flow rate to $1500 \mathrm{~mL} \cdot \mathrm{min}^{-1}$, achieving the highest degradation (up to $75.8 \%$ for chlorpyrifos and $56.7 \%$ for carbaryl, respectively), at the air flow rate of $1000 \mathrm{~mL} \cdot \mathrm{min}^{-1}$.

\subsubsection{Treatment Time}

Considering the influence of the length of treatment time on food quality as Dorraki et al. [8] mentioned, the degradation of diazinon on cucumber surface was accelerated by increasing the plasma treatment time. Plasma treatment times ranging from $20 \mathrm{~s}$ to $60 \mathrm{~s}$ were selected for this research. The effects of plasma treatment time on the elimination of chlorpyrifos and carbaryl under operation parameters set at $1000 \mathrm{~Hz}$ frequency, optimal discharge $20 \mathrm{~W}$ power and $1000 \mathrm{~mL} \cdot \mathrm{min}^{-1}$ air flow rate are shown in Figure 2c. Regardless of the different pesticide treated, the elimination efficacy increased significantly $(p<0.05)$ at all treatment times. Therefore, the treatment time of $60 \mathrm{~s}$ was chosen as an appropriate operation parameter.

\subsubsection{Frequency}

Based on the above-obtained optimal parameters, this part separately examined the effect of plasma frequency on the degradation of chlorpyrifos and carbaryl, as shown in Figure 2d. With the increase of frequency, the degradation rate of both pesticides increased significantly. Hence, it can be figured out that plasma treatment of the two pesticides achieved the highest removal efficiency (up to $86.2 \%$ for chlorpyrifos and $66.6 \%$ for carbaryl) at an air flow rate of $1000 \mathrm{~mL} \cdot \mathrm{min}^{-1}$ for $60 \mathrm{~s}, 20 \mathrm{~W}$ discharge power and $1200 \mathrm{~Hz}$ frequency. The residues of pesticides were reduced from the initial concentration of $1.93 \pm 0.02 \mathrm{mg} \cdot \mathrm{kg}^{-1}$ to final $0.27 \mathrm{mg} \cdot \mathrm{kg}^{-1}$ for chlorpyrifos and from an initial $1.89 \pm 0.01 \mathrm{mg} \cdot \mathrm{kg}^{-1}$ to a final concentration of $0.63 \mathrm{mg} \cdot \mathrm{kg}^{-1}$ for carbaryl. All of these were below the MRL of cereals $\left(<0.5 \mathrm{mg} \cdot \mathrm{kg}^{-1}\right.$ for chlorpyrifos and $<1.0 \mathrm{mg} \cdot \mathrm{kg}^{-1}$ for carbaryl) according to Chinese National Standard GB/T 2763-2016 [20].

\subsection{Evaluation of Physical Changes on the Treated Corn Surface}

\subsubsection{SEM Micrographs}

An investigation of the changes caused by air-plasma treatment of corn on the surface topography using the chosen operating parameters $\left(1000 \mathrm{~mL} \cdot \mathrm{min}^{-1}\right.$ of air flow rate, power of $20 \mathrm{~W}$ and frequency of $1200 \mathrm{~Hz}$ for $30 \mathrm{~s}$ and $60 \mathrm{~s}$, respectively) was performed. SEM micrographs of control and treated corn samples are shown in Figure 3. It can be clearly seen that the surface of corn treated for $30 \mathrm{~s}$ and $60 \mathrm{~s}$ displayed roughness with some cracks and depressions similar to the results reported by Sarangapani et al. [21] and Thirumdas et al. [22] which were due to surface etching caused by high-energy electrons and reactive species. As the exposure time increases, the roughness on the corn surface continued to increase, as shown in Figure 3c, however, after air-plasma treatment for $30 \mathrm{~s}$ and $60 \mathrm{~s}$, there was no significant damage and basically no change. 


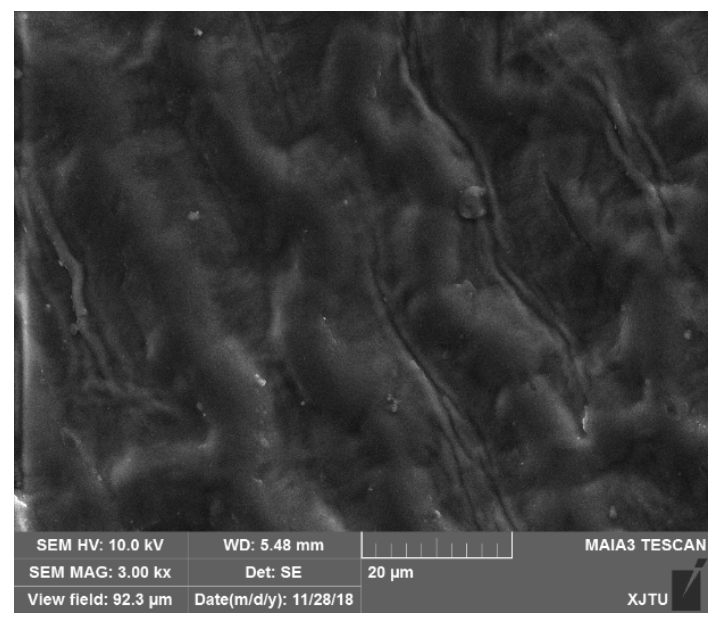

(a)

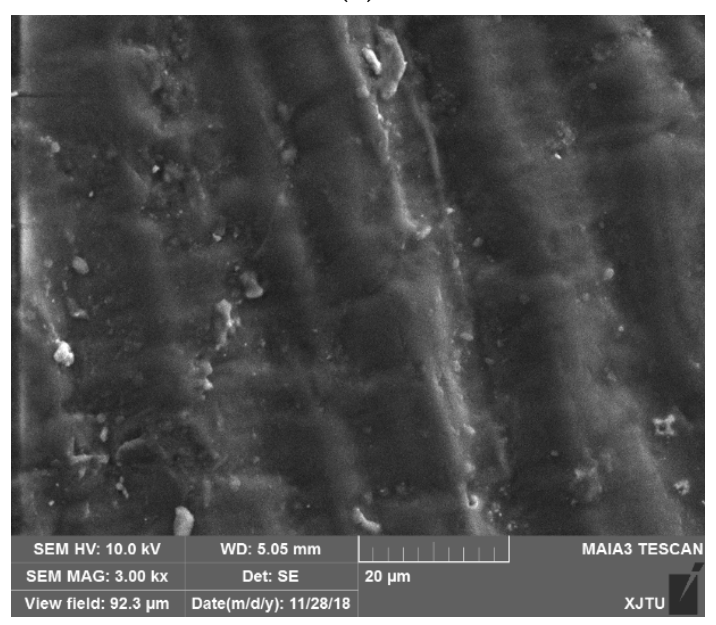

(b)

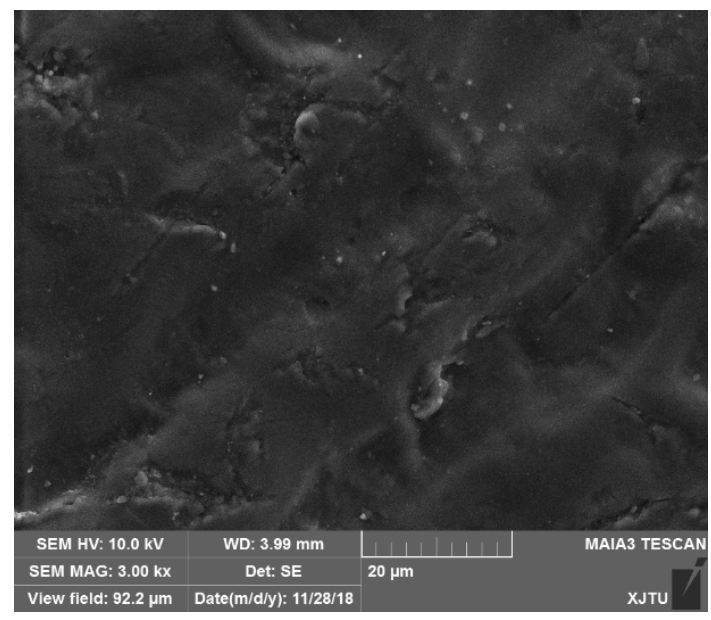

(c)

Figure 3. SEM images at $3000 \times, 10 \mathrm{kV}$ of corn (a) control; (b) $30 \mathrm{~s}$; (c) $60 \mathrm{~s}$ at power of $20 \mathrm{~W}$, flow rate of $1000 \mathrm{~mL} \cdot \mathrm{min}^{-1}$, frequency of $1200 \mathrm{~Hz}$.

\subsubsection{Contact Angle and Surface Free Energy}

The changes in contact angle, surface free energy $\left(\gamma_{s}\right)$, polar component $\left(\gamma_{s}{ }^{P}\right)$ and dispersion component $\left(\gamma_{s}{ }^{d}\right)$ of corn before and after air-plasma treatment using the optimal degradation parameters $\left(20 \mathrm{~W}, 1000 \mathrm{~mL} \cdot \mathrm{min}^{-1}\right.$ and $\left.1200 \mathrm{~Hz}\right)$ as a function of time $(0-60 \mathrm{~s})$ are shown in Table 1. After $60 \mathrm{~s}$ air-plasma treatment, the contact angle of water and 
diiodomethane on the corn surface decreased from an initial value of $74.91^{\circ}$ to a final value of $54.07^{\circ}$ and from an initial value of $52.16^{\circ}$ to $43.24^{\circ}$, respectively, both of which represented a significant decrease $(p<0.05)$. In order to further investigate the reason(s) for the contact angle decrease, the surface free energy and its components were measured. From Table 1, it could be figured out that the surface free energy and polar component of treated corn showed significant increases $(p<0.05)$ from initial $36.44 \mathrm{~mJ} \cdot \mathrm{m}^{-2}$ to $50.16 \mathrm{~mJ} \cdot \mathrm{m}^{-2}$ for surface free energy and from $9.08 \mathrm{~mJ} \cdot \mathrm{m}^{-2}$ to final value of $22.33 \mathrm{~mJ} \cdot \mathrm{m}^{-2}$ for polar component. However, there were no significant changes in the dispersion component.

Table 1. The variation of contact angle, surface free energy and its components of corn before and after air-plasma treatment as a function of time at power of $20 \mathrm{~W}$, flow rate of $1000 \mathrm{~mL} \cdot \mathrm{min}^{-1}$ and frequency of $1200 \mathrm{~Hz}$.

\begin{tabular}{|c|c|c|c|c|c|}
\hline \multirow{2}{*}{$\begin{array}{l}\text { Treatment } \\
\text { Time (s) }\end{array}$} & \multicolumn{2}{|c|}{ Contact Angle $\left(^{\circ}\right)$} & \multicolumn{3}{|c|}{$\begin{array}{l}\text { Surface Free Energy and Its Components } \\
\qquad\left(\mathrm{mJ} \cdot \mathrm{m}^{-2}\right)\end{array}$} \\
\hline & $\mathrm{H}_{2} \mathrm{O}$ & $\mathrm{CH}_{2} \mathrm{I}_{2}$ & $\gamma_{s}$ & $\gamma_{s}^{p}$ & $\gamma_{s}^{d}$ \\
\hline Control & $74.91 \pm 2.40^{\mathrm{a}}$ & $52.16 \pm 2.89^{a}$ & $36.44 \pm 1.44^{\mathrm{d}}$ & $9.08 \pm 1.61^{c}$ & $27.35 \pm 1.83^{a}$ \\
\hline 20 & $63.60 \pm 1.54^{\mathrm{b}}$ & $46.84 \pm 2.58^{b}$ & $43.51 \pm 1.04^{c}$ & $15.25 \pm 1.06^{b}$ & $28.00 \pm 0.85^{\mathrm{a}}$ \\
\hline 30 & $59.22 \pm 3.44^{b c}$ & $44.80 \pm 2.99^{b}$ & $46.11 \pm 2.11^{b}$ & $17.97 \pm 2.78^{b}$ & $28.24 \pm 1.86^{a}$ \\
\hline 40 & $57.18 \pm 2.55^{c}$ & $46.43 \pm 2.58^{b}$ & $46.89 \pm 1.89 \mathrm{ab}$ & $19.98 \pm 1.72^{\mathrm{ab}}$ & $26.91 \pm 1.22^{\mathrm{a}}$ \\
\hline 50 & $55.18 \pm 1.42^{c}$ & $45.48 \pm 1.24^{b}$ & $48.28 \pm 0.94^{\mathrm{a}}$ & $21.94 \pm 2.45^{\mathrm{ab}}$ & $26.34 \pm 2.20^{a}$ \\
\hline 60 & $54.07 \pm 2.25^{\mathrm{c}}$ & $43.24 \pm 1.61^{c}$ & $50.16 \pm 0.72^{a}$ & $22.33 \pm 1.26^{\mathrm{a}}$ & $27.83 \pm 0.96^{a}$ \\
\hline
\end{tabular}

Values with different letters in the same column are significantly different $(p<0.05, n=3)$.

\subsection{Evaluation of Nutrient Changes in Treated Corn}

Table 2 displays the changes in moisture content, starch content, acid value and vitamin $B_{2}$ content of corn before and after air-plasma treatment using the optimal degradation parameters $\left(20 \mathrm{~W}, 1000 \mathrm{~mL} \cdot \mathrm{min}^{-1}\right.$ and $\left.1200 \mathrm{~Hz}\right)$ as a function of time $(0 \mathrm{~s}, 30 \mathrm{~s}, 60 \mathrm{~s})$. Clearly, among these samples, the remarkable decrease $(p<0.05)$ of moisture content and starch content were observed as a function of treatment time, and starch content showed a significant decrease $(p<0.05)$ from an initial content of $63.4 \mathrm{~g} \cdot 100 \mathrm{~g}^{-1}$ to a final value of $57.4 \mathrm{~g} \cdot 100 \mathrm{~g}^{-1}$ after $60 \mathrm{~s}$ of treatment. However, the acid value of samples showed a significant increase $(p<0.05)$ as a function of exposure time. The control plasma treatment values for $30 \mathrm{~s}$ and $60 \mathrm{~s}$ corn samples were $41.2 \mathrm{~g} \cdot 100 \mathrm{~g}^{-1}, 42.9 \mathrm{~g} \cdot 100 \mathrm{~g}^{-1}$ and $44.8 \mathrm{~g} \cdot 100 \mathrm{~g}^{-1}$, respectively. Meanwhile, the vitamin $B_{2}$ content of control and treated corn samples showed no significant difference $(p>0.05)$.

Table 2. The content changes of treated corn nutrients moisture, acid value, starch and vitamin $B_{2}$ compare with control corn at power of $20 \mathrm{~W}$, flow rate of $1000 \mathrm{~mL} \cdot \mathrm{min}^{-1}$ and frequency of $1200 \mathrm{~Hz}$.

\begin{tabular}{|c|c|c|c|c|}
\hline Plasma & Moisture & Starch & Acid Value & Vitamin $B_{2}$ \\
\hline Treatment & $\left(g \cdot 100 g^{-1}\right)$ & $\left(g \cdot 100 g^{-1}\right)$ & $\left(g \cdot 100 g^{-1}\right)$ & $\left(\mu \mathrm{g} \cdot 100 \mathrm{~g}^{-1}\right)$ \\
\hline Control & $13.8 \pm 0.15^{a}$ & $63.4 \pm 0.26^{a}$ & $41.2 \pm 0.24^{\mathrm{c}}$ & $49.0 \pm 0.15^{\mathrm{a}}$ \\
\hline $30 \mathrm{~s}$ & $13.4 \pm 0.10^{b}$ & $58.3 \pm 0.30^{b}$ & $42.9 \pm 0.31^{b}$ & $51.4 \pm 0.25^{a}$ \\
\hline $60 \mathrm{~s}$ & $12.9 \pm 0.15^{c}$ & $57.4 \pm 0.15^{\mathrm{c}}$ & $44.8 \pm 0.30^{\mathrm{a}}$ & $49.8 \pm 0.89^{a}$ \\
\hline
\end{tabular}

Values with different letters in the same column are significantly different $(p<0.05, n=3)$.

\section{Discussion}

The plasma treatment at $1000 \mathrm{~mL} \cdot \mathrm{min}^{-1}$ of air flow rate for $60 \mathrm{~s}$, discharge power of $20 \mathrm{~W}$ and frequency of $1200 \mathrm{~Hz}$, removed chlorpyrifos and carbaryl residues on corn, achieving a best efficiency of up to $86.2 \%$ and $66.6 \%$ removal, respectively, and the pesticide residue concentrations on treated corn were below the MRL of cereals. For discharge power, a significant degradation $(p<0.05)$ of chlorpyrifos and carbaryl could be obtained due to the increase of plasma discharge power. This phenomenon is attributed to the fact an increasing discharge power enhances the intensity of the discharge electric field generating more reactive species and increases the possibility of collisions between pesticide molecules 
and reactive species, which directly leads to efficient pesticide degradation. Similar results were also reported by Bai et al. [23] and Gao et al. [24]. In addition, due to the difference in the pesticides' structures, the degradation of carbaryl is lower than that of chlorpyrifos. As is known to all, the naphthalenol structure in carbaryl is more stable than the nitrogen heterocyclic ring in chlorpyrifos, the latter is more susceptible to radical oxidation and attack by high-energy electrons, showing a better elimination effect than the former. Besides, for a system with fixed energy input, the amount of air flow rate determined the amount and residence time of reactive species produced by the plasma discharge [23]. With the increase of gas flow rate, the plasma reaction species in the reactor are more numerous, but the residence time of plasma reactive species is shorter [25]. The greater the number of reactive species, the greater the collision probability with pesticide molecules, which is more conducive to pesticide degradation. The longer the residence time, the more conducive to pesticide degradation. As can be seen from Figure 2b, when the gas flow rate increased from $150 \mathrm{~mL} \cdot \mathrm{min}^{-1}$ to $1000 \mathrm{~mL} \cdot \mathrm{min}^{-1}$, the pesticide degradation rate increased. The reason is assumed to be that the positive effect of the increase in the number of reactive species on pesticide degradation was greater than the negative effect of the reduction of residence time on degradation. When the gas flow rate increased from $1000 \mathrm{~mL} \cdot \mathrm{min}^{-1}$ to $1500 \mathrm{~mL} \cdot \mathrm{min}^{-1}$, the pesticide degradation rate decreased which we hypothesize is because the gas flow rate was too large and the residence time was very short. Although the number of reactive species was also increasing, the effect of residence time on pesticide degradation was greater than that of reactive species. Moreover, longer exposure time to the plasma discharge zone is more favorable for generated reactive species to attack pesticide molecules resulting in the higher elimination efficacy of pesticides, which is in agreement with the studies of Sarangapani et al. [9]. Finally, a reason for the increased degradation effect as the frequency increased is that a higher frequency delivers more energy input to the plasma reactor increasing the number and average energy of reactive species, enhancing the collision possibility and the competence of reactive species to break chemical bonds of pesticides [26].

In addition the changes in corn surface morphology led to water molecules penetrating easily and this increased the effective surface area of corn, shortening the cooking time and improving the hydrophilicity [22]. The cracks and depressions on the surface promoted the action of adsorption and spreading of water decreasing the contact angle of treated corn. It can be concluded that the polar component plays a major role in the increase of surface free energy from the fact that the surface free energy includes the polar component and the dispersion component. The formation of polar groups and new oxidized functional groups like $-\mathrm{OH},-\mathrm{C}=\mathrm{O}$, and $-\mathrm{COOH}$ on the surface of treated corn caused the increase in the polar component which was also reported by Pankaj et al. [27]. The oxygen-containing functional groups may enhance the Lewis base (electron donor) parameter which is beneficial for increasing the hydrophilic character [28,29]. In short, the improvement of hydrophilicity of corn after air-plasma treatment is attributed to surface etching and the introduction of polar functional groups on surface, shortening the cooking time [30].

Furthermore, plasma treatment had effects on the nutritional quality of maize. For moisture content, it was decreased with increased treatment time. This phenomenon is mainly explained by the following two aspects. On the one hand, the plasma caused surface etching on the surface of the corn. This behavior destroyed the surface coating of corn enhancing the diffusion of water molecules from the corn interior to the surrounding environment [31]. On the other hand, the moisture of corn collided with reactive species in the plasma discharge zone, converting into oxygen-containing groups and hydroxyl radicals [32]. The cumulative effect of these two phenomena reduced the moisture content of corn, which is conducive to better corn storage. Also, the starch content in treated corn decreased slightly compared with control corn, but within an acceptable range [33]. This is because the plasma-generated reactive species directly modify and interact with the surface starch of corn through surface etching, resulting in some fragments, which was also in agreement with other studies [34]. Besides, plasma treatment of corn stimulated the 
activity of $\alpha$-amylase to accelerate the decomposition of starch, shortening the germination time of seeds [35]. This has been reported by Chen et al. [36], who determined $\alpha$-amylase activity in rice after plasma treatment and found that its activity was significantly enhanced. Therefore, the reduction of starch content of treated corn was attributed to the combination of direct etching of reactive species and decomposition of $\alpha$-amylase. However, the acid value of the treated corn was significant increased with increasing treatment time. The reasons for the increase in acid value were that unsaturated fatty acids in corn are oxidized in the strongly oxidizing environment formed by the air plasma discharge. Meanwhile, the surface etching of corn enhanced the oxidation of fatty acids, resulting in its value increasing as the exposure time increases. This increase in acid value meant a slight decrease in the storage value of the treated corn, however, according to China's corn storage quality standard(GB/T 20570-2015) [37], the acid value of corn is required to be less than $65 \mathrm{~g} \cdot 100 \mathrm{~g}^{-1}$, so the plasma treatment had a negligible impact on the storage quality of corn and will not have an impact on food safety. Finally, the vitamin $B_{2}$ content of control and treated corn samples showed no significant differences. One possible explanation is that plasma as a surface tool had a limited influence on vitamin $B_{2}$ of corn interior, which only acted on trace amounts of vitamin $B_{2}$ on the surface of corn. What's more, vitamin $B_{2}$ is chemically relatively stable. Therefore, the effect of plasma on vitamin $B_{2}$ of corn was negligible.

\section{Conclusions}

Plasma achieved maximum degradations of chlorpyrifos and carbaryl of up to $86.2 \%$ and $66.6 \%$, respectively, using an air flow rate for $1000 \mathrm{~mL} \cdot \mathrm{min}^{-1}$, power of $20 \mathrm{~W}$, treatment time for $60 \mathrm{~s}$ and frequency of $1200 \mathrm{~Hz}$. The pesticide residues in treated corn were controlled below the MRL for grains. Meanwhile, the reduction in moisture content was beneficial to corn storage; the reduction of starch content from an initial value of $63.4 \mathrm{~g} \cdot 100 \mathrm{~g} \mathrm{~g}^{-1}$ to a final value of $57.4 \mathrm{~g} \cdot 100 \mathrm{~g}^{-1}$ slightly affected the industrial application value of product corn starch; the acid value increased within the acceptable range of the national standard; there was no significant difference in vitamin $B_{2}$ content. Generally, plasma can be considered a green and safe technology to remove pesticide residues on the surface of corn without compromising its quality.

Author Contributions: Conceptualization, H.L.; methodology, H.L.; resources, H.L.; data curation, X.F.; writing—original draft preparation, X.F. and D.G.; writing—review and editing, D.G.; visualization, D.G.; supervision, H.L. All authors have read and agreed to the published version of the manuscript.

Funding: This research was supported financially by the Natural Science Foundation of China (no. 31871889) and the Natural Science Basic Research Plan in Shaanxi Province of China (no. 2017JM5067).

Institutional Review Board Statement: Not applicable.

Informed Consent Statement: Not applicable.

Data Availability Statement: The data presented in this study are available on request from the corresponding author.

Acknowledgments: The authors are grateful for the helpful comments and constructive suggestions offered by the three anonymous reviewers.

Conflicts of Interest: The authors declare no conflict of interest.

\section{References}

1. Kermani, M.; Dowlati, M.; Gholami, M.; Sobhi, H.R.; Azari, A.; Esrafili, A.; Yeganeh, M.; Ghaffari, H.R. A Global Systematic Review, Meta-Analysis and Health Risk Assessment on the Quantity of Malathion, Diazinon and Chlorpyrifos in Vegetables. Chemosphere 2021, 270, 12. [CrossRef]

2. Malalgoda, M.; Simsek, S. Pesticide Residue in Grain-Based Food: Effects on Health, Grain Quality, and Chemical Properties of Biomacromolecules. Cereal Chem. 2021, 98, 8-16. [CrossRef] 
3. Mahugija, J.A.M.; Kayombo, A.; Peter, R. Pesticide Residues in Raw and Processed Maize Grains and Flour from Selected Areas in Dar Es Salaam and Ruvuma, Tanzania. Chemosphere 2017, 185, 137-144. [CrossRef]

4. Cullen, P.J.; Lalor, J.; Scally, L.; Boehm, D.; Milosavljevic, V.; Bourke, P.; Keener, K. Translation of Plasma Technology from the Lab to the Food Industry. Plasma Process. Polym. 2018, 15, 1700085. [CrossRef]

5. Khanh Thi Kim, P.; Huan Tai, P.; Brennan, C.S.; Phimolsiripol, Y. Nonthermal Plasma for Pesticide and Microbial Elimination on Fruits and Vegetables: An Overview. Int. J. Food Sci. Technol. 2017, 52, 2127-2137.

6. Ikmal Misnal, M.F.; Redzuan, N.; Firdaus Zainal, M.N.; Raja Ibrahim, R.K.; Ahmad, N.; Agun, L. Emerging Cold Plasma Treatment on Rice Grains: A Mini Review. Chemosphere 2021, 274, 129972. [CrossRef]

7. Gavahian, M.; Sarangapani, C.; Misra, N.N. Cold Plasma for Mitigating Agrochemical and Pesticide Residue in Food and Water: Similarities with Ozone and Ultraviolet Technologies. Food Res. Int. 2021, 141, 110138. [CrossRef]

8. Dorraki, N.; Mahdavi, V.; Ghomi, H.; Ghasempour, A. Elimination of Diazinon Insecticide from Cucumber Surface by Atmospheric Pressure Air-Dielectric Barrier Discharge Plasma. Biointerphases 2016, 11. [CrossRef]

9. Sarangapani, C.; O'Toole, G.; Cullen, P.J.; Bourke, P. Atmospheric Cold Plasma Dissipation Efficiency of Agrochemicals on Blueberries. Innov. Food Sci. Emerg. Technol. 2017, 44, 235-241. [CrossRef]

10. Misra, N.N.; Pankaj, S.K.; Walsh, T.; O’Regan, F.; Bourke, P.; Cullen, P.J. In-Package Nonthermal Plasma Degradation of Pesticides on Fresh Produce. J. Hazard. Mater. 2014, 271, 33-40. [CrossRef]

11. Liu, T. Analysis of Pesticide Residues in Vegetables and Rice and Dynamics of Chlorpyrifos Digestion in Paddy Fields. Master's Thesis, Northeast Agricultural University, Harbin, China, 2012. (In Chinese).

12. Wang, J.D.; You, J.L. Analysis of chlorpyrifos by HPLC. Pesticide 1993, 5, 20-21. (In Chinese)

13. Yang, Y.; Yang, X. Determination of carbaryl and carbofuran in corn by HPLC. Food Food Ind. 2013, 20, 109-111. (In Chinese)

14. Fujii, M.; Kato, K.; Imai, M.; Kuwabara, H.; Awano, M.; Hashizaki, K.; Taguchi, H. The Comparison of Surface Free Energy of Human, Yucatan Micropig, and Hairless Mouse Skins and Influence of Surfactant on Surface Free Energy of the Skin. Biol. Pharm. Bull. 2019, 42, 295-298. [CrossRef] [PubMed]

15. Determination of Water Content in Food; Gb/T 5009.3-2016; Standards Press of China, 2016.

16. Determination of Starch Content in Food; Gb/T 5009.9-2016; Standards Press of China, 2016.

17. Wang, Z.F. Effects of different storage conditions on fatty acid value of maize. Mod. Food 2020, 18, 16-17. (In Chinese)

18. Determination of Fat Acidity Value of Grain and Oilseeds; Gb/T 5510-2011; Standards Press of China, 2011.

19. Determination of Vitamin B2 Content in Food; Gb/T 5009.85-2016; Standards Press of China, 2016.

20. National Food Safety Standard-Maximum Residue Limits of Pesticides in Food; Gb/T 2763-2016; Standards Press of China, 2016.

21. Sarangapani, C.; Devi, Y.; Thirundas, R.; Annapure, U.S.; Deshmukh, R.R. Effect of Low-Pressure Plasma on Physico-Chemical Properties of Parboiled Rice. Lwt-Food Sci. Technol. 2015, 63, 452-460. [CrossRef]

22. Thirumdas, R.; Saragapani, C.; Ajinkya, M.T.; Deshmukh, R.R.; Annapure, U.S. Influence of Low Pressure Cold Plasma on Cooking and Textural Properties of Brown Rice. Innov. Food Sci. Emerg. Technol. 2016, 37, 53-60. [CrossRef]

23. Bai, Y.; Chen, J.; Yang, Y.; Guo, L.; Zhang, C. Degradation of Organophosphorus Pesticide Induced by Oxygen Plasma: Effects of Operating Parameters and Reaction Mechanisms. Chemosphere 2010, 81, 408-414. [CrossRef]

24. Gao, L.; Sun, L.; Wan, S.; Yu, Z.; Li, M. Degradation Kinetics and Mechanism of Emerging Contaminants in Water by Dielectric Barrier Discharge Non-Thermal Plasma: The Case of 17ß-Estradiol. Chem. Eng. J. 2013, 228, 790-798. [CrossRef]

25. Yang, Y.T. Study on Decomposition of Carbon Tetrafluoride by Surface Wave Plasma. Master's Thesis, Dalian Maritime University, Dalian, China, 2020. (In Chinese)

26. Hatzisymeon, M.; Tataraki, D.; Rassias, G.; Aggelopoulos, C.A. Novel Combination of High Voltage Nanopulses and in-Soil Generated Plasma Micro-Discharges Applied for the Highly Efficient Degradation of Trifluralin. J. Hazard. Mater. 2021, 415, 125646. [CrossRef]

27. Pankaj, S.K.; Bueno-Ferrer, C.; O’Neill, L.; Tiwari, B.K.; Bourke, P.; Cullen, P.J. Characterization of Dielectric Barrier Discharge Atmospheric Air Plasma Treated Chitosan Films. J. Food Process. Preserv. 2017, 41. [CrossRef]

28. Gotoh, K.; Yasukawa, A.; Kobayashi, Y. Wettability Characteristics of Poly(Ethylene Terephthalate) Films Treated by Atmospheric Pressure Plasma and Ultraviolet Excimer Light. Polym. J. 2011, 43, 545-551. [CrossRef]

29. Vesel, A.; Zaplotnik, R.; Primc, G.; Mozetič, M. Evolution of the Surface Wettability of Pet Polymer Upon Treatment with an Atmospheric-Pressure Plasma Jet. Polymers 2020, 12, 87. [CrossRef] [PubMed]

30. Sujka, M.; Jamroz, J. Characteristics of Pores in Native and Hydrolyzed Starch Granules. Starch-Starke 2010, 62, 229-235. [CrossRef]

31. Zhang, X.-L.; Zhong, C.-S.; Mujumdar, A.S.; Yang, X.-H.; Deng, L.-Z.; Wang, J.; Xiao, H.-W. Cold Plasma Pretreatment Enhances Drying Kinetics and Quality Attributes of Chili Pepper (Capsicum Annuum L.). J. Food Eng. 2019, 241, 51-57. [CrossRef]

32. Zou, J.J.; Liu, C.J.; Eliasson, B. Modification of Starch by Glow Discharge Plasma. Carbohydr. Polym. 2004, 55, 23-26. [CrossRef]

33. Liu, C.C.; Zhang, M.N.; Wu, X.P.; Pei, X.X.; Dang, J.Y.; Zhang, Y.Q.; Xi, Y.J.; Wang, B.S.; Song, X.J.; Li, S.P.; et al. Effects of ret-rogradation of microspraying fertilizer on nitrogen uptake, grain yield and quality of summer maize. Soil Fertil. Sci. China 2019, 6, 108-113. (In Chinese)

34. Wongsagonsup, R.; Deeyai, P.; Chaiwat, W.; Horrungsiwat, S.; Leejariensuk, K.; Suphantharika, M.; Fuongfuchat, A.; Dangtip, S. Modification of Tapioca Starch by Non-Chemical Route Using Jet Atmospheric Argon Plasma. Carbohydr. Polym. 2014, 102, 790-798. [CrossRef] 
35. Sarangapani, C.; Thirumdas, R.; Devi, Y.; Trimukhe, A.; Deshmukh, R.R.; Annapure, U.S. Effect of Low-Pressure Plasma on Physico-Chemical and Functional Properties of Parboiled Rice Flour. Lwt-Food Sci. Technol. 2016, 69, 482-489. [CrossRef]

36. Chen, H.H.; Chang, H.C.; Chen, Y.K.; Hung, C.L.; Lin, S.Y.; Chen, Y.S. An Improved Process for High Nutrition of Germinated Brown Rice Production: Low-Pressure Plasma. Food Chem. 2016, 191, 120-127. [CrossRef]

37. Guidelines for Evaluation of Maize Storage Character; Gb/T 20570-2015; Standardization Administration of the People's Republic of China: Beijing, China, 2015. 